\title{
Coregulation of the $\mathrm{Na} / \mathrm{K}$ pump and the h-current as a mechanism for robust neuromodulation
}

\author{
William Barnett $^{1 *}$, Daniel Kueh², Ronald Calabrese², Gennady Cymbalyuk ${ }^{1}$ \\ From 24th Annual Computational Neuroscience Meeting: CNS*2015 \\ Prague, Czech Republic. 18-23 July 2015
}

To achieve the behavioral flexibility necessary for survival in a variable environment, neuronal circuits have to produce activity over a broad range of functional characteristics. Central pattern generators (CPGs), rhythmically active neuronal networks that control motor functions such as breathing, swimming, and walking, are ideal systems for addressing questions about how neuromodulation efficiently adjusts network output to meet environmental demands. Neuromodulators modify the dynamics of CPGs by orchestrating changes in multiple ionic channels and the electrogenic pump. The $\mathrm{Na}+\mathrm{K}+$ pump has been implicated as critical in the dynamics of CPGs [1,2]. In the leech heartbeat CPG, the $\mathrm{Na}+/ \mathrm{K}+$ pump is a target for neuromodulation. The neuropeptide myomodulin decreases the burst period; it increases the h-current and decreases the $\mathrm{Na}+/ \mathrm{K}+$ pump current.

We developed a model of the leech heart interneuron $(\mathrm{HN})$ including the $\mathrm{Na}+\mathrm{K}+$ pump current and intracellular $\mathrm{Na}+$ dynamics. We separately considered the $\mathrm{HN}$ and pairs of HNs coupled through mutual inhibition that form half-center oscillators (HCOs). HCOs form the kernel of the leech heartbeat CPG. To investigate the role of the h-current and the $\mathrm{Na}+\mathrm{K}+$ pump current, we changed corresponding biophysical parameters of these currents. We investigated eight model instantiations representing combinations of three experimental treatments: the blockade of chemical synapses representing application of bicuculline, the blockade of h-current representing application of $\mathrm{Cs}+$, and the enhancement of the h-current and inhibition of the $\mathrm{Na}+/ \mathrm{K}+$ pump current representing the application of myomodulin.

Experiments with Cs+ and myomodulin showed the separate effects of myomodulin on the h-current and the $\mathrm{Na}+/ \mathrm{K}+$ pump current [1]. Experimental application of myomodulin decreases the period of oscillatory activity by $17 \%$. Application of Cs+ increases the period of bursting by $24 \%$ relative to control. The application of myomodulin in addition to Cs+ decreases the period of bursting by $12 \%$ relative to treatment with $\mathrm{Cs}+$. The model captures the qualitative trends in change of cycle period observed in experiments with myomodulin and Cs+. Since the application of myomodulin decreases the period of activity when the h-current is present or absent, the $\mathrm{Na}+/ \mathrm{K}+$ pump current plays a significant role in the dynamics of the $\mathrm{HCO}$.

We investigated activity of the model with different values of the maximal conductance of the h-current, $\bar{g}_{h}$ and the maximal pump current, $I_{\text {Pump }}^{\mathrm{Max}}$, for isolated neurons and HCOs. We found ranges of parameters where neurons showed bursting activity. In the $\mathrm{HCO}$, we identified the region of the parameter space that supported functional bursting activity. Joint changes of $\mathrm{I}_{\text {Pump }}^{\mathrm{Max}}$ and $\overline{\mathrm{g}}_{\mathrm{h}}$ allows neurons to preserve functional activity over a larger span of $\mathrm{I}_{\text {Pump }}^{\mathrm{Max}}$ and $\overline{\mathrm{g}}_{\mathrm{h}}$ and to produce functional activity with a larger range of period.

\section{Acknowledgements}

Supported by NINDS 1 R01 NS085006 to RLC and by NSF PHY-0750456 to GSC.

\section{Authors' details}

'Neuroscience Institute, Georgia State University, Atlanta, GA 30303, USA. 2Department of Biology, Emory University, Atlanta, GA 30322, USA.

\section{Published: 18 December 2015}

\section{References}

1. Tobin AE, Calabrese RL: Myomodulin increases Ih and inhibits the NA/K pump to modulate bursting in leech heart interneurons. I Neurophysiol 2005, 94(6):3938-3950.

\footnotetext{
* Correspondence: gcymbalyuk@gsu.edu

'Neuroscience Institute, Georgia State University, Atlanta, GA 30303, USA

Full list of author information is available at the end of the article
} 
2. Zhang $H Y$, Sillar $K T$ : Short-term memory of motor network performance via activity-dependent potentiation of $\mathrm{Na}+/ \mathrm{K}+$ pump function. Curr Biol 2012, 22(6):526-531.

doi:10.1186/1471-2202-16-S1-P42

Cite this article as: Barnett et al:: Coregulation of the $\mathrm{Na} / \mathrm{K}$ pump and

the h-current as a mechanism for robust neuromodulation. BMC

Neuroscience 2015 16(Suppl 1):P42.

Submit your next manuscript to BioMed Central and take full advantage of:

- Convenient online submission

- Thorough peer review

- No space constraints or color figure charges

- Immediate publication on acceptance

- Inclusion in PubMed, CAS, Scopus and Google Scholar

- Research which is freely available for redistribution

Submit your manuscript at 